\title{
Olhar-se sem cabelos - Estudo de enfermagem sobre mulheres com alopecia decorrente da quimioterapia antineoplásica
}

\author{
My reflexion with no hair - nursing study on women with alopecia reactions resulting from cancer \\ chemotherapy
}

\author{
Marilei de Melo Tavares e Souza ${ }^{\dagger *}$, Fabrícia de Mello Cordeiro Moura \\ Monteiro da Silva ${ }^{\S}$, Pamela dos Santos Costall, Nébia Maria Almeida de Figueiredo ${ }^{\circ}$, Joanir Pereira \\ $\operatorname{Passos}^{\square}$
}

Como citar esse artigo. Tavares e Souza MM; Moura, FMC; da Silva, ASM; Costa, PS; de Figueiredo, NMA; Olharse sem cabelos - estudo de enfermagem sobre mulheres com alopecia decorrente da quimioterapia antineoplásica . Revista de Saúde. 2017 Jul./Dez.; 08 (2): 16-22.

\begin{abstract}
Resumo
Mulheres passam a ter o corpo fragmentado durante tratamento oncológico, com queda dos cabelos decorrente da quimioterapia antineoplásica. Objetiva-se identificar reações de mulheres submetidas à quimioterapia antineoplásica frente à perda de seu cabelo; e discutir as implicações advindas da alopecia para implantação de estratégias para o cuidado e enfermagem a clientes com câncer em quimioterapia antineoplásica. Esta foi uma pesquisa qualitativa com abordagem metodológica da Sociopoética incluindo 30 mulheres em tratamento quimioterápico no Centro Oncológico de Vassouras, RJ, Brasil. Os dados da pesquisa foram obtidos durante dinâmicas de sensibilidade/criatividade e entrevistas, com aprovação do CEP, em cumprimento a Resolução 510/16 do CNS/MS. Os resultados indicam que o corpo holístico (família e religião) representam o momento em que vivenciaram queda dos cabelos; o corpo belo (feminilidade) não foi afetado pela alopecia, e as entrevistadas importavam-se em estar vivas; corpo ecológico (animais e paisagens) representaram a fase como sendo de transformação; o corpo doente/mutilado (alopecia) foi considerado passageiro. Este estudo permitiu identificar a feminilidade entre as mulheres, mesmo sem cabelos, e se configura como contribuição para o cuidado de enfermagem à mulheres com alopecia em decorrência da quimioterapia.
\end{abstract}

Palavras-chave: Alopecia; Enfermagem; Neoplasias; Quimioterapia antineoplásica.

\begin{abstract}
Hair loss due to cancer treatment fragments women's bodies. This study identifies the reactions of women who underwent antineoplastic chemotherapy in regards to hair loss and discusses the implications of alopecia with the objective of creating strategies for care and nursing of clients with cancer during chemotherapy. This was a qualitative research with a sociopoetic approach including thirty women undergoing chemotherapy at the Oncology Centre in Vassouras, RJ, Brazil. Data was obtained during sensibility/creativity sessions and interviews, with Ethics approval according to CNS/MS resolution 510/16. Results indicate that the holistic body (family and religion) represented the moment the women experienced hair loss; the beautiful body (femininity) was not affected by the alopecia, and the women cared most about being alive; the ecological body (animals and landscapes) represented the phase of hair loss as being one of transformation, and the mutilated/sick body (alopecia) was considered temporary. This study allowed identification of femininity among female chemotherapy patients, even in the face of hair loss, and contributes to the nursing and care of women facing alopecia during chemotherapy.
\end{abstract}

Keywords: Alopecia; Neoplasms; Nursing; Cancer chemotherapy.

\section{Introdução}

O câncer é um problema de saúde pública: a Organização Mundial da Saúde (OMS) estimou que até o ano 2030, são esperados 27 milhões de casos incidentes de câncer, salientando que ocorrerão 17 milhões de mortes e 75 milhões de pessoas vivas com câncer. Têm-se uma previsão de um aumento progressivo de casos nos países de baixas e médias rendas que hoje são mais acometidos por doenças infectocontagiosas e parasitárias (1).

Os tratamentos dependem do estádio da neoplasia podendo ser a cirurgia, a radioterapia e a quimioterapia antineoplásica, tendo cada um suas consequências para o corpo da mulher, para o equilíbrio emocional e vida social, cultural, econômica e religiosa. Pode desestruturar o paciente, conviver com o fator possível de morte, o que faz com que muitas vezes se apeguem

\footnotetext{
Afiliação dos autores: $\uparrow$ Doutoranda pelo Programa de Pós-Graduação em Enfermagem e Biociências - PPGENFBIO da Universidade Federal do Estado do Rio de Janeiro/UNIRIO.

Professora Assistente na Universidade Severino Sombra/USS

\$ Enfermeira, graduada pela Universidade Severino Sombra/USS.

§ Doutorando do Programa de Pós-graduação em enfermagem da Escola de Enfermagem Anna Nery da Universidade Federal do Rio de Janeiro/UFRJ. Prof. do Curso de Enfermagem da USS.

|| Pós-Graduanda no Curso de Enfermagem em UTI da Universidade Severino Sombra/USS. Enfermeira pela Universidade Severino Sombra/USS

O Professora Emérita da Escola de Enfermagem Alfredo Pinto da Universidade Federal do Estado do Rio de Janeiro/UNIRIO. Doutora em Enfermagem pela Escola de Enfermagem Anna Nery da Universidade Federal do Rio de Janeiro/UFRJ. Orientadora de Doutorado e Mestrado na UNIRIO.

$\square$ Professora Titular da Escola de Enfermagem Alfredo Pinto da Universidade Federal do Estado do Rio de Janeiro/UNIRIO. Doutora em Enfermagem pela Universidade de São Paulo/USP. Coordenadora do Doutorado em Enfermagem e Biociências-PPGENFBIO/UNIRIO. Orientadora de Doutorado e Mestrado Acadêmico em Enfermagem - PPGENF/UNIRIO.

*E-mail para correspondência: marileimts@hotmail.com Recebido em: 12/04/17. Aceito em: 26/10/17.
} 
a Deus para enfrentar e alcançar a cura. Por ser uma doença com representação de ingrata, que leva à morte, traz tristeza, amedronta (2).

Mulheres portadoras de câncer passam a ter o seu corpo fragmentado a partir da cirurgia nos casos de neoplasia mamária, em que é realizada segmentectomia, quadrantectomia, mastectomia e a quimioterapia antineoplásica, o que pode ocasionar queda dos cabelos, escurecimento das unhas, hiperpigmentação da pele e assim vão aos poucos perdendo seus traços de identidade feminina. Além dos traços estéticos elas convivem diariamente com o medo de perder a luta para a morte.

Considerada pela mulher com câncer como um dos aspectos mais difíceis de serem enfrentados durante o tratamento, a alopecia um efeito colateral representativo no tratamento quimioterápico. A enfermagem através da integralidade pode contribuir para a aceitação desse processo, contudo precisa lançar um olhar integral a essa clientela com práticas efetivas voltadas à promoção da saúde dessas mulheres (3).

A alopecia dentre os diversos efeitos colaterais produzidos pelos quimioterápicos é um dos fatores que mais causa inquietação na mulher por demostrar que está doente. A alopecia caracteriza-se pela perda dos cabelos, com atrofia total ou parcial do folículo piloso, levando a haste do cabelo despencar. Aparece aproximadamente duas a três semanas com o início do processo quimioterápico, podendo persistir durante todo o tratamento (4). É considerado um dos aspectos emocionais mais difíceis a serem enfrentados pela mulher, pode atuar negativamente no cotidiano, na elaboração da imagem corporal e na vida sexual da mulher (5).

Embora os cabelos voltem a crescer após o termino da terapêutica antineoplásica, é evidente como essa reação adversa é devastadora psicologicamente, estressante, traumática e dolorosa emocionalmente para as mulheres (6).

A cirurgia e a radioterapia atuam de forma local e produzem consequências diferentes dependendo do estágio da neoplasia, e a quimioterapia antineoplásica atua de forma sistêmica, podendo promover diversos efeitos indesejáveis no corpo da mulher dentre eles: náuseas, vômito, constipação, anorexia, mucosite, diarréia, neutropenia, fadiga, alterações nas unhas, hiperpigmentação da pele e alopecia.

Estudos demonstraram que o enfermeiro é o profissional que tem contato permanente com a mulher durante todo o tratamento quimioterápico. Embora os cuidados de enfermagem em relação à alopecia da mulher com câncer devem ser focados nas múltiplas dimensões, consequências e mudanças que o tratamento quimioterápico traz à mulher, a maior preocupação ocorre com o vômito (3).

Assegurar qualidade de vida da mulher em tratamento quimioterápico por meio de ações educativas é uma das funções do enfermeiro. Dentre a equipe multiprofissional que assiste a mulher portadora de câncer, o enfermeiro permanece maior tempo em contato com mulher permitindo, cuidado integral, amparado pelo diagnóstico de enfermagem, tanto como prestador de cuidados bem como educador em saúde (7).

A atuação da Enfermagem na área oncológica, requer além de conhecimentos teóricos e práticos, habilidades para conduzir a atuação profissional. Olhar para além da patologia, atentando também para os cuidados subjetivos, com ações que favoreçam o vínculo com cliente e família, suporte e apoio emocional (8), tendo em vista que a enfermagem tem influência no resultado da assistência recebida pelo paciente (9).

Há necessidade de se promover a reflexão dos enfermeiros sobre a alopecia, reação adversa tão temida pelas clientes em tratamento quimioterápico antineoplásico. Essa discussão tecida pode proporcionar outro olhar sobre o saber-fazer do enfermeiro enquanto educador, ao buscar maneiras sensíveis, criativas para melhorar a autoimagem e autoestima da mulher em tratamento antineoplásico.

Vários enfermeiros podem tratar essa toxicidade dermatológica com mínima importância porque não promove risco de vida para a cliente, mas é necessário que o enfermeiro compreenda qual a representação que o cabelo tem para cada cliente, tanto social, cultural, como religiosa, para atender de forma mais criteriosa às suas necessidades. Trata-se de uma reflexão para que os enfermeiros transcendam a visão reducionista da terapêutica antineoplásica e compreendam o corpo da mulher como inteiro e não fragmentado.

O estudo teve por objeto reações de alopecia de mulheres submetidas ao tratamento quimioterápico antineoplásico. Com isso objetivamos identificar as reações dessas mulheres frente à perda de seu cabelo e discutir as implicações advindas da alopecia para implantação de estratégias para o cuidado de enfermagem à clientes com câncer durante a quimioterapia antineoplásica.

Acreditamos que esse estudo contribuirá com a enfermagem na prática oncológica exercitando seu papel no processo de cuidar e no que diz respeito ao papel enquanto educador durante o tratamento quimioterápico, para um melhor atendimento das necessidades humanas básicas (autoestima) da mulher através da visão das mesmas ao se verem sem os cabelos.

\section{Métodos}

Pesquisa qualitativa com abordagem 
metodológica da sociopoética. Esta abordagem se adequa ao método qualitativo (10) que trabalha com o universo dos significados, dos motivos, das aspirações, das crenças, dos valores e das atitudes, responde a questões muito particulares e se ocupa, nas ciências sociais, com um nível de realidade que não pode ou não deveria ser quantificado.

A enfermagem é arte e como tal é sensitiva e para propor um novo caminho para a produção do conhecimento [...] é preciso convocar a criatividade, sensualidade, a sensibilidade, a memória, a imaginação enfim, tudo que se pode chamar de "poética" - do grego "poieîn", criar - é uma ajuda preciosa na liberação do saber grupal e pessoal implícito, num sentido crítico (11).

Enquanto que a sociopoética gera um processo de "criação/desestabilização, nos sujeitos, permitindolhes liberar coisas escondidas, esquecidas, recalcadas". Assim o conhecimento produzido transcende apenas a "vontade de saber", pois atinge dimensões da pessoa, a qual se revela nos corpos físico, intelectual e espiritual (12).

Relacionado à posição dos autores identifica-se que essa abordagem é adequada a essa pesquisa, pois gera oportunidade para os sujeitos "exteriorizarem" o seu imaginário acerca da alopecia decorrente do tratamento quimioterápico antineoplásico.

Destacam seis momentos da sociopoética: escolha do "tema orientador" pelo (a) pesquisador (a). É dado o ponto de partida que sofrerá mudança com o processo da pesquisa (11).

Após delimitar o tema o pesquisador (a) e o grupo envolvido na pesquisa delimitam qual é a "demanda de saber" do grupo que não tem obrigação de ser igual ou parecida com o desejo do pesquisador. A sociopoética é um método dialógico, aceita uma pluralidade de vozes, uma polifonia semântica e conceitual o que permite obter dados coletivos e individuais. $E$ os dados produzidos entre o pesquisador e co-pesquisador são analisados em grupo.

Em um segundo momento, o pesquisador analisa isoladamente os dados e depois restitui ao grupo os resultados da análise. Assim os co-pesquisadores passam a avaliar a análise, os resultados $\mathrm{e}$ as interpretações do pesquisador.

Após esse momento de análise e confronto emergem novas perguntas que não são mais provenientes só do pesquisador, mas são a produção dos co-pesquisadores. Através dessas novas perguntas, se for o desejo do grupo, pode se começar uma "transformação do mundo". O que buscamos é a produção de singularidade expressa na subjetividade de cada participante (13).

A pesquisa teve como cenário o Centro Oncológico, localizado no Município de Vassouras, RJ, local em que podem ser encontradas pessoas em tratamento quimioterápico antineoplásico com uso de drogas que promovem alopecia. Realizou-se uma Solicitação de Campo, assegurando oportunidade da coleta dos dados.

Os participantes da pesquisa foram 30 mulheres clientes em quimioterapia antineoplásica neo-adjuvante ou adjuvante após o primeiro ciclo do protocolo quimioterápico estabelecido.

A coleta dos dados ocorreu em grupo e de forma individual. As participantes receberam orientações sobre a pesquisa por intermédio do pesquisador.

Posteriormente foram coletados os dados, sendo todas as participantes informadas, através do Termo de Consentimento Livre e Esclarecido (TCLE), sobre os objetivos do estudo, sendo assegurados os aspectos éticos da pesquisa com seres humanos conforme a Resolução 510/16. Cabe ressaltar que foi mantido o anonimato e também foram informados sobre a possibilidade de se recusar a participar da pesquisa, bem como interromper sua participação em qualquer momento. $\mathrm{O}$ projeto que originou o estudo foi submetido à avaliação do comitê de ética em pesquisa CEP/UNIRIO com aprovação $\mathrm{n}^{\circ}$. 479.666.

Quanto à técnica de pesquisa, foi realizada uma dinâmica de sensibilidade e criatividade, técnica esta que permite uma maior integração entre a pesquisadora e os sujeitos do estudo, proporcionando que eles imaginem através de pinturas ou colagens o ser mulher sem cabelos em decorrência do tratamento quimioterápico (14). Através dos desenhos, pinturas e colagens é possível visualizar o que parece invisível aos olhos, e assim emerge uma imagem que representa o que pensam, sendo assegurada sua liberdade de expressão, após o qual se realizou uma entrevista não estruturada para coletar as interpretações dos participantes sobre as representações realizadas.

O uso de dinâmicas utilizando a criatividade e arte no âmbito da saúde promove a construção de saberes a partir da vivência do discurso do outro e de lugares por ele transitados, pois para o imaginário tudo é possível. Ao vivenciar este lugar, o sujeito se permite vivenciar a experiência que emerge do processo subjetivo, constrói saberes próprios da vivência do outro, podendo vir a transformar sua forma de agir (15).

Após o primeiro momento foi apresentada às participantes da pesquisa a seguinte questão: como eu me vejo sem cabelos após o tratamento quimioterápico?

Foram disponibilizados lápis de cor, giz de cera, canetinhas, revistas para que os sujeitos realizassem uma produção artística através de desenho, corte e colagem para representar o ser mulher sem cabelos em decorrência do tratamento quimioterápico.

Em outro momento as participantes explicaram o porquê e o significado atribuído ao seu desenho, pintura ou colagem e listaram sinais, gestos, jeitos e palavras 
da (o) enfermeira (o) que demonstram o impacto da alopecia como reação do tratamento quimioterápico antineoplásico.

Para a fase de análise os dados foram organizados conforme a convergência e divergências das respostas, permitindo assim a categorização a partir da produção criativa e sensível dos sujeitos e pelas suas falas. Foi realizada a análise temática, que consistiu em descobrir núcleos de sentido que constituem uma comunicação cuja presença ou frequência apresentem significado para o objetivo analítico visado. Esse tipo de análise desdobra-se em três etapas: pré-análise, onde é realizada a leitura flutuante e formulação de hipóteses e objetivo, seguida de exploração do material e o tratamento dos dados obtidos para posterior interpretação (16).

\section{Resultados e discussões}

\section{Criações Artísticas e Sensíveis das mulheres com alopecia}

Esta categoria foi definida pelas criações artísticas e sensíveis das clientes com alopecia decorrente do tratamento quimioterápico antineoplásico, ligadas a figuras de: família, paisagens, pessoas sorridentes, pessoas demonstrando sua crença religiosa, pessoas felizes, vários sentimentos foram expressos diante a queda dos cabelos.

Assim após apresentação das criações artísticas e sensíveis dos dados foram subdivididas as expressões em 4 itens: Corpo Holístico, Corpo Belo, Corpo Ecológico e Corpo Doente/Multilado. Das imagens reproduzidas pelas mulheres que participaram do estudo, 7 (23\%) representam o Corpo Holístico, 13 (43\%) representam o Corpo Belo, 6 (20\%) representam o corpo Ecológico e 4 (14\%) representam o Corpo Doente/Mutilado.

Estudos apontam que, a atuação da enfermagem deve ter um olhar atento para a questão da alopecia, considerado o efeito colateral mais difícil para as pacientes e enfatizam que existem práticas alternativas para disfarçar a queda dos cabelos. A enfermagem deve identificar lacunas que merecem maior exploração como: o modo de cuidar dos cabelos durante a quimioterapia, o que pode influenciar em sua queda; o uso de lenços e perucas e sua influência sobre o crescimento do cabelo. Balizando, portanto, a assistência prestada pelo enfermeiro e os sentimentos e efeitos colaterais apresentados pela mulher com alopecia, visando à reabilitação e a ressocialização (3).

Foi constatada a relevância de cada mulher entrevistada em sua visão interior, onde se propuseram a expressar seu sentimento diante da queda dos cabelos. Sendo evidenciado o sofrimento das mulheres que diariamente se encontram em tratamento que como consequência, apresentam alopecia.

Indo de encontro com a literatura, onde o tratamento da alopecia gera alterações emocionais, físicas e sociais, ou seja, afeta-a em suas múltiplas dimensões (17).

\section{Corpo Holístico}

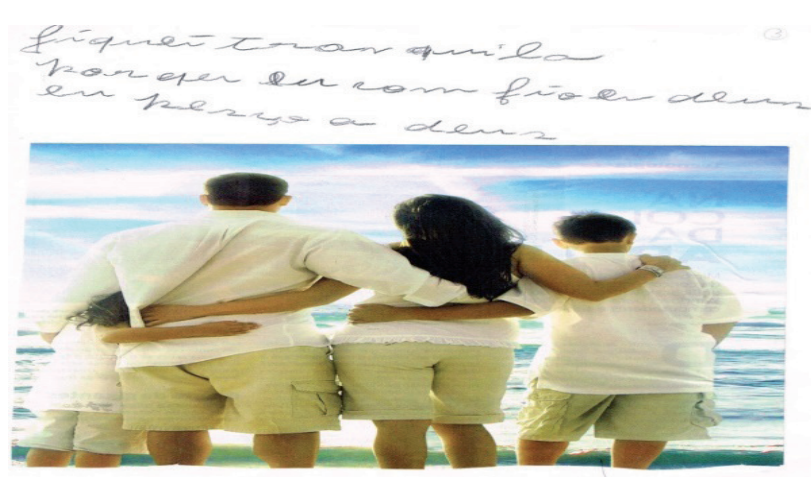

Figura 1. Confiança na família e Religião. Fonte: Dados da pesquisa.

"Fiquei tranquila porque eu confio em Deus ..."

As clientes utilizaram imagens de famílias e figuras religiosas para representar esse momento que vivenciaram a queda dos cabelos dando ênfase na importância da família e da religião para esse momento difícil. Sentimentos expressos a partir das representações: confiança, felicidade, fé, família, beleza, cura, libertação, festa, tristeza, solidão, perda, aceitação e gratidão.

O câncer, hoje em dia em nossa sociedade, embora com as várias formas de tratamento, ainda é intitulado como uma doença incurável, que evidencia a proximidade da morte. Assim, os pacientes e os familiares, diante da desesperança e do sofrimento causado pela descoberta da doença, buscam na espiritualidade e na religião sentido positivo ou negativo às experiências que estão sendo vivenciadas (18).

É viável entender que os termos "espiritualidade" e "religião" estão relacionados, mas, apesar de muitas vezes serem utilizados com o mesmo significado, tais significados não apresentam as mesmas características. A espiritualidade é mais ampla e pessoal, está relacionada a um conjunto de valores pessoais, completude interior, harmonia, conexão com os outros; estimula solidariedade pelos outros e interesse por si; um sentido para vida, a natureza e o universo. É aquilo que dá sentido à vida, independente de sua religião, e, dessa maneira, produz capacidade de suportar sentimentos debilitantes de culpa, raiva e ansiedade; além disso, os aspectos espiritualistas podem gerar energias positivas 
e melhorar a qualidade de vida dessas mulheres que resultaram a alopecia durante o tratamento (18).

Todos os tipos de religião têm seus fundamentos, algumas se baseiam em diversas análises filosóficas, que explicam o que somos e porque viemos ao mundo. Outras se sobressaem pela fé e outras em extensos ensinamentos éticos. Religião, no sentido figurado, significa qualquer atividade realizada com rígida frequência (18).

\section{Corpo Belo}

A maioria das pacientes representou que sua feminilidade não foi afetada pela alopecia e ressaltou que importava estarem vivas. Foi definida pelas criações artísticas e sensíveis das participantes relacionando alopecia decorrente do tratamento quimioterápico antineoplásico à figuras de mulheres bonitas, com cabelos e sorridentes. Sentimentos expressos a partir das representações: queda de cabelo como fase, queda de cabelo espelho e fantasia, espelho cabelo e beleza, cabelo e força, viver com ou sem cabelos, cabelo peruca e lenço, cabelo conforto, força e família, cabelo essência careca - raiz e força, normal não ter cabelos.

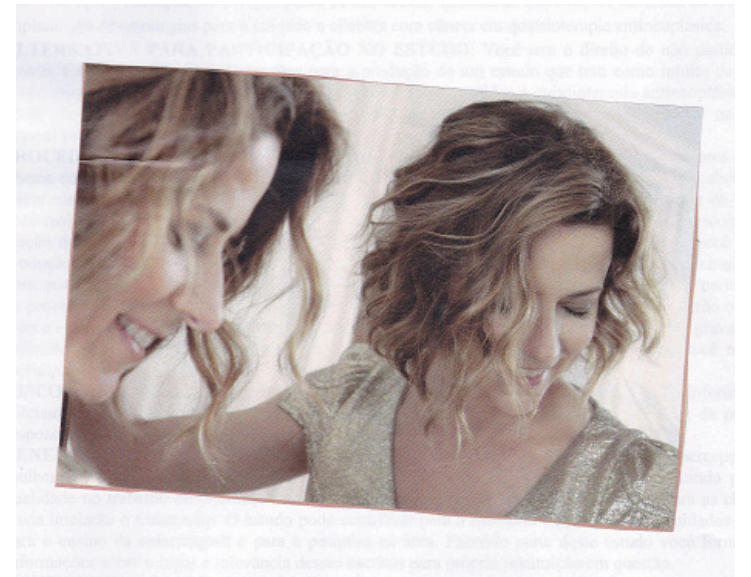

Figura 2. Espelho, cabelo e beleza. Fonte: Dados da pesquisa.

"A beleza vem através do cabelo. Mexe muito."

Buscando se concentrar no processo de tratamento da quimioterapia, sendo gratas a Deus por ainda terem a chance de lutar pela vida. Não que a perda dos cabelos não tenha afetado o psicológico dessas mulheres ofertando às mesmas um desconforto e timidez em lidar com a sociedade, mas diante da doença, optaram por encarar a realidade e se adaptar às formas onde possam se sentir mais a vontade com sua própria imagem.

Formas essas que se adaptaram a um novo estilo de viver e de ser para que assim pudessem se sentir menos "diferentes" e "mais aceitas" na sociedade, fundamentado pelo fato que as mulheres que foram objeto dessa pesquisa, se sentem incomodadas com o olhar das pessoas que as veem na rua de lenço, de peruca ou até mesmo carecas. Os resultados indicaram que a preocupação predominante dessas mulheres foi à sobrevivência e não a imagem corporal.

Os familiares têm função muito importante na vida dessas mulheres que estão passando por esse processo de tratamento que se depara com a alopecia. E mais, elas se deparam e se confrontam em seus próprios "eus" diante do espelho. Percebe-se que há uma dificuldade maior em se ver "diferente" nesse momento novo, onde suas expectativas se voltam para a esperança de viver bem e saudável se empenhando e depositando nesse apoio familiar, a base necessária para conseguir seguir em frente nessa jornada rumo ao seu benefício interior visando sua cura e buscando a felicidade.

Considerando que as neoplasias têm como características a longa permanência no processo de tratamento, a possibilidade de recidiva e a necessidade de intervenção, é natural que a sua ocorrência altere o meio familiar, resaltando que expõe todos os membros da família a grandes perdas, entre elas as de saúde, bem-estar, financeira e de equilíbrio físico, mental e emocional, que envolvem toda uma estrutura. Estas características são evidenciadas na importância do papel da família diante da responsabilidade de cuidar desse membro doente (18).

\section{Corpo Ecológico}

Utilizaram imagens de animais e paisagens para representar essa fase como sendo de transformação. Foi definida pelas criações artísticas e sensíveis ligadas a figuras de: nuvens, árvores, brincos, gatos, pato, flores, pássaros, planeta terra. Sentimentos expressos: relacionamento conjugal e sexual, cabelo, flores, renascimento e autoestima, vida dividida, sem sentido, descontentamento, valor de uma joia para Deus, liberdade.

O cuidado com um ente querido com neoplasia vem tornando-se uma realidade para muitas famílias atualmente. O diagnóstico dessa doença tão grave afeta tanto o sujeito enfermo que está passando pelo

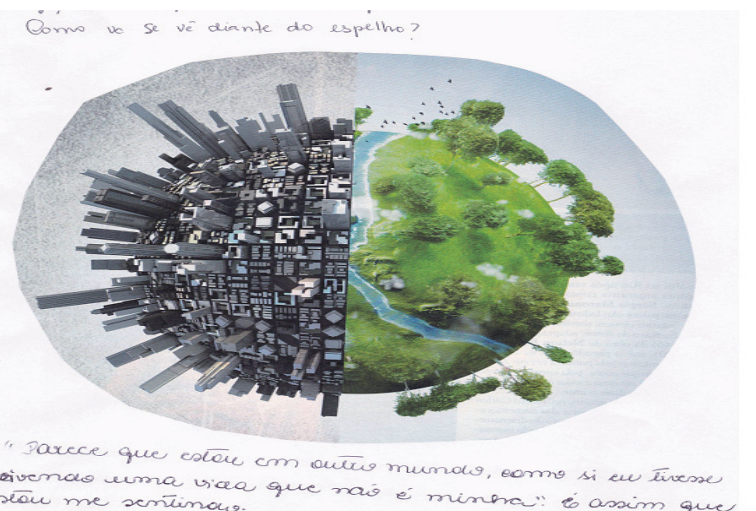

Figura 3. Transformação. Fonte: Dados da pesquisa.

"Parece que estou em outro mundo, como se eu estivesse vivendo uma vida que não é minha. É assim que estou me sentindo." 
tratamento como o seio familiar, acarretando várias mudanças na vida dessas pessoas que se propõem a apoiar essa paciente que expira muitos cuidados, fazendo com que haja uma reorganização na rotina cotidiana dessa família que precisará fazer grandes mudanças para os cuidados exigidos pela doença e o tratamento dessa mulher. A demanda de cuidados expirados pelo câncer e pelas necessidades de saúde da paciente influenciam diretamente a vida e a rotina desse cuidador, o que, consequentemente, pode alterar sua qualidade de vida (19).

A palavra câncer sempre remete a posições estigmatizadoras pela sociedade, as quais repousam nas formas de tratamento, bastante agressivas levando a muitas vezes reações adversas para aquelas que se descobrem com câncer porque sabem de antemão que terão mudanças na imagem corporal e das múltiplas possibilidades de morte (1).

Jogada no mundo em uma situação de doença e de tratamento como expectativa de cura, essa mulher é conduzida para si mesma e suas possibilidades mais interiores e próprias. Estando no modo de ser do impessoal e, portanto, presa a linguagem tradicionalista que dita à existência cotidiana da sociedade, existindo com o medo do tratamento que a expõe diante dos outros e de si mesma, acaba por encontrar-se (20).

Apesar de terem sido orientadas quanto a este efeito colateral, é visível o medo, o desespero e a angústia dessas mulheres diante desta perda que lhes parecia tão devastadora. Esta perda que parecia ser a mais importante de tantas outras perdas (21).

\section{Corpo Doente/mutilado}

Mostraram que mesmo com a alopecia elas se mantiveram conscientes de que a alopecia é passageira. Definida pelas criações artísticas e sensíveis das clientes com alopecia decorrente do tratamento quimioterápico antineoplásico, ligadas a figuras de: pessoas sem cabelos demonstrando estarem em tratamento quimioterápico e sorrindo. Sentimentos expressos a partir das representações: não se entregar a doença, cabelo, vida e fé, preocupação do lenço e desconfiança da doença, cuidado, bem-estar, encantamento.

Acabaram por perceber diante das dificuldades, que a doença vinha acarretar na vida de cada uma delas, uma brusca mudança, onde o mais sensato seria adaptar as mudanças fisiológicas ocorridas em seus corpos com a sua vida cotidiana. As mulheres submetidas ao tratamento quimioterápico para o câncer em consequência do qual perdem seu cabelo, mostraramse como pessoas que encaram esta perda com tamanha tristeza e dor, que pode ser maior que aquela causada pela gravidade da doença, o sofrimento do tratamento.

Entende-se que é com a produção de novos

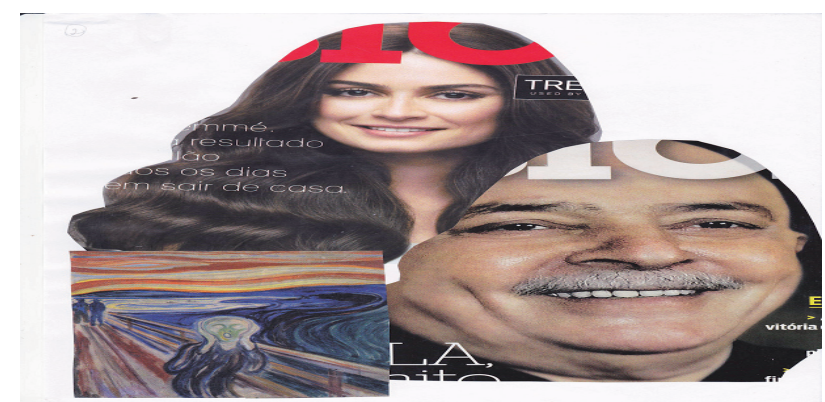

Figura 4. Uso do lenço desconfiança do câncer. Fonte: Dados da pesquisa.

"Fiquei preocupada com as pessoas que me viam de lenço na rua. "Claro que eles iam desconfiar de alguma coisa."

conhecimentos que temos a possibilidade de vislumbrar novos caminhos e, com eles, uma melhor compreensão e, até mesmo, respostas para as inquietações surgidas em nossa prática diária de assistir ao outro (20).

$\mathrm{O}$ cabelo tem a função de proteger o couro cabeludo, pois possuem receptores nervosos que funcionam como sensores, os quais aumentam a proteção quando necessário. É um apêndice do corpo tegumentar que ao longo da história está associado ao "status" social, político, cultural e religioso. Seu jeito de ser preso, o corte, o formato e a cor refletem tendências de expressão pessoal, além de características estéticas, sexo, idade e em algumas culturas é símbolo de fertilidade, sinal de saúde e "status". É uma estrutura corporal que comunica o papel sócio-sexual, pode ser um símbolo de poder, riqueza e "sobrevive à morte". Raspar a cabeça pode indicar um ritual utilizado para marcar intencionalmente uma transição social, e implica modificação de "status" e condição social, pode também indicar a participação em rituais religiosos ou ingressar em alguma ordem religiosa. A raspagem dos cabelos ao longo da história como rejeição às vaidades do mundo, sinal de arrependimento, desprezo e degradação (6).

Foi possível compreender que a dimensão da angústia dessas mulheres que enfrentam o tratamento de quimioterapia e que no olhar diferenciado e sensível dessas mulheres, elas almejam dias melhores, onde a fé e a vontade de viver são os combustíveis primordiais para alcançar com êxito a cura e lidar com as reações adversas ocasionadas pelo tratamento de quimioterapia antineoplásica.

\section{Conclusão}

Buscamos com o estudo identificar as reações de mulheres submetidas à quimioterapia antineoplásica. Investigamos as expressões dos sentimentos relacionados a alopecia.

As produções realizadas pelas mulheres contribuem para a percepção de que pacientes em tratamento quimioterápico têm sobre si mesmas e a 
alopecia, assim colaborando para maior qualidade no trabalho da enfermagem.

Nas produções, algumas mulheres produziram em suas expressões artísticas, figuras em cortes e outras, desenhando com lápis de cor. Onde as expressões se deram em ilustrações de pessoas bonitas, sorridentes, aves, plantas e flores e a imagem mais comentada entre todas, é a figura de famílias felizes. Onde foram fatores indispensáveis para a estrutura de todo trabalho.

Os resultados apontam para o fato que o descobrimento do câncer remete a posições estigmatizadoras pela sociedade, as quais se fazem em forma de tratamento, que é bastante agressivo levando a várias reações adversas para o corpo das mulheres que se descobrem com câncer, porque já sabem que terão muitas mudanças em seu corpo e das múltiplas possibilidades de morte durante o tempo que durar o tratamento.

$\mathrm{Na}$ apresentação das criações sensíves das participantes, o cabelo teve a maior representatividade, sendo considerado ícone da beleza feminina, denotando sinais de personalidade, de feminilidade e sensualidade. Sua queda pode afetar de forma significativa as clientes em tratamento quimioterápico antineoplásico por alterar sua autoimagem e autoestima, levando à ansiedade, revolta, medo e angústia.

Em síntese, diferente das outras reações adversas decorrentes do tratamento antineoplásico a alopecia afeta o exterior do corpo feminino não podendo ser ocultada causando constrangimento nas clientes ao realizarem suas atividades diárias.

\section{Referências}

1. Brasil. Ministério da Saúde. Estimativa 2012: incidência de câncer no Brasil/ Instituto Nacional de Câncer José Alencar Gomes da Silva. Rio de Janeiro: INCA; 2011.

2. Silva SED, Araújo JS, Chaves MO et al. Social representations about the disease of women with cervico-uterine cancer. J. res.: fundam. care. [online]. $2016 \mathrm{jan} . / \mathrm{mar} ; 8(1): 3667-3678$.

3. Baitelo TC, Reis APA, Gradim CVC. A atuação da enfermagem na alopecia da mulher com câncer de mama: revisão integrativa. Revista de enfermagem UFPE on line. 2015 nov; 9(11):9898-905.

4. Brasil. Ministério da saúde. Bases do tratamento do câncer 2008 cap. 06. Brasília: Ministério da Saúde; 2008.

5. Santos DB, Vieira EM. Imagem corporal de mulheres com câncer de mama: uma revisão sistemática da literatura. Rev de Ciên e Saúde Colet [Internet]. 2011;15(5):2511-2522.

6. Shimada CS. Efeitos Adversos no Tratamento Quimioterápico: Uma Visão para Enfermeiros e Farmacêuticos. $1^{\mathrm{a}}$ ed. São Paulo: Planmark; 2009.

7. Lopes MHBM, Moura AA, Raso S, Vedovato TG, Ribeiro MAS. Diagnósticos de enfermagem no pós-operatório de mastectomia. Esc Anna Nery (impr.)2013; 17(2):354-360.

8. Brito KCFV, Souza SR. As necessidades de cuidado do cliente oncológico hospitalizado: aplicação da taxonomia nanda. Rev Fund Care [online]. 2017 abr/jun; 9(2):327-332.

9. Pires D. A Enfermagem enquanto disciplina, profissão e trabalho. Rev bras enferm [Internet]. 2009;62(5):739-44.

10. Minayo MCS (Org.). Deslandes SF, Gomes R. Pesquisa Social: teoria, método e criatividade. 25. ed. Rio de Janeiro: Vozes; 2007.

11. Santos I, Gauthier J. A Sócio-Poética: fundamentos teóricos, técnicas diferenciadas de pesquisa, vivência. - Rio de Janeiro: UERJ, DEPEXT, NAPE; 1996.

12. Santos I, Gauthier J. Enfermagem: Análise Institucional e Sócio-Poética. - Rio de Janeiro: Escola de Enfermagem Anna Nery/UFRJ; 1999.

13. Tavares CMM. Como desenvolver experimentações estéticas para produção de dados na pesquisa sociopoética e abordagens afins? Revista Pró-UniverSUS. 2016; 07 (3): 26-31.

14. Figueiredo NMA, Carvalho V. O corpo da enfermeira como instrumento do cuidado. Rio de Janeiro: Revinter, 1999.

15. Souza MMT, Tavares CMM, Gama NL, Passos JP. Primer Drama - A Technical Education Product. J. res.: fundam. care. [online]. 2015 out./dez.; 7(4):3543-3553.

16. Minayo MCS. O desafio do conhecimento: pesquisa qualitativa em saúde. 12. ed. São Paulo: HUCITEC; 2010.

17. Santos LR, Tavares GB, Reis PED. Análise das respostas comportamentais ao câncer de mama utilizando o modelo adaptativo de Roy. Rev enferm UERJ [Internet]. 2012;16(03):459-465.

18. Guerrero GP, Zago MMF, Sawada NO, Pinto MH. Relação entre espiritualidade e câncer: perspectiva do paciente. Rev. bras. enferm.[online]. 2011; 64(1):53-59.

19. Fornazari SA, Ferreira RR. Religiosidade/espiritualidade em pacientes oncológicos: qualidade de vida e saúde. Psic.: Teor. e Pesq. [online]. 2010; 6 (2): 265-272.

20. Camargo TC. O ex-sistir feminino enfrentando a quimioterapia para o câncer de mama: um estudo de enfermagem na ótica de Martin Heidegger/ Teresa Caldas Camargo. Rio de Janeiro: UFRJ; 2000. XII, 180 p.

21. Camargo TC, Souza IEO. Enfermagem à mulher em tratamento quimioterápico: uma análise compreensiva do assistir. Revista Brasileira de Enfermagem, 1998;51(3):357-368. 